\title{
The Language-Culture Link in Exolinguistic Tourism Service \\ Encounters ${ }^{1}$
}

\section{(El vínculo lenguaje-cultura en encuentros exolingüísticos dentro del servicio turístico)}

Joan Marie Boes Naderer ${ }^{2}$

Universidad de Costa Rica, Costa Rica

\begin{abstract}
This article discusses four aspects related to cultural and linguistic interaction within exolinguistic communication prevalent in tourism. The first aspect refers to the role of culture as an essential part of linguistic exchanges, and the second explains the unconscious nature of socialization and language processes. The third aspect is the pragmatics of communication in exolinguistic service interactions, and the fourth approaches the role of habitus in intercultural communication in tourism.

\section{resumen}

Este artículo trata cuatro aspectos relacionados con la interacción entre la cultura y el idioma, en el contexto exolingüístico del sector turístico. Un primer aspecto se refiere al papel de la cultura en los intercambios lingüísticos; el segundo explica la naturaleza inconsciente de los procesos de la socialización y el idioma; el tercer aspecto se refiere a la pragmática de la comunicación en las interacciones exolingüísticas de servicio; y el cuarto aspecto expone el papel del habitus en la comunicación intercultural en el turismo.
\end{abstract}

1 Recibido: 7 de abril de 2015; aceptado: 27 de setiembre de 2015.

2 Departamento de Artes, Filosofía y Letras, Sección de Lenguas Modernas. Correo electrónico: joan.boesnaderer@ucr.ac.cr. 
Keywords: exolinguistic interactions; culture; language processes; intercultural communication

Palabras clave: interacciones exolingüísticas; culture; procesos de lenguaje, comunicación intercultural

\section{Introduction}

The inclusion of culture as an inseparable aspect of language acquisition and use is perhaps one of the most dramatic transformations that Applied Linguistics has undergone in the last century. This transformation began with Dell Hymes' challenge to Chomsky's seminal distinction between language competence and language performance in connection with a generative universal grammar that rules the acquisition of a language. In Hymes' perspective, neither of Chomsky's categories considered the real social contexts in which language is used and appropriated by the learner. ${ }^{3}$ In other words, Hymes ${ }^{4}$ noted that Chomsky's theory left no room for dealing with language learning when heterogeneous speech communities and their constitutive socio-cultural features are involved in such process.

The term communicative competence arose from those observations leading to the concept of interactional competence under sociocultural circumstances, pointing to the relevance of social interactions in language teaching and learning. In this regard, Hallaway contributes the idea that when language is in use, it is then that all its functions and meanings operate together. ${ }^{5}$

Like the above, numerous other language theorists, such as $\mathrm{Ca}$ nale, Swain, Krashen, and those tied to the Humanistic Approaches, have contributed to the gradual development of theories which explicitly sustain that language and culture are intricately intertwined

3 Janice Yalden, The Communicative Syllabus. Evolution, Design and Implementation (London: Prentice Hall International, 1987) 16.

4 Dell Hymes, "Models of Interaction of Language and Social Life," John Joseph Gumperz and Dell Hymes, Directions in Sociolinguistics: The Ethnography of Communication (Oxford: Basil Blackwell, 1986) 35.

5 Yalden, 19. 
as part of one another. Regardless of these plausible efforts, many aspects remain unsolved especially for understanding the socialization and commoditization of language and culture under the impact of globalized tourism, and the processes in which learners and users are immersed within and beyond their particular native communities.

\section{Culture as an Inherent Aspect of Language Proficiency}

The National Center for Cultural Competence defines culture as an "integrated pattern of human behavior that includes thoughts, communications, languages, practices, beliefs, values, customs, courtesies, rituals, manners of interacting and roles, relationships and expected behaviors of a racial, ethnic, religious or social group; and the ability to transmit the above to succeeding generations. ${ }^{\prime \prime}$ This means that language is not only part of culture, but actually defines culture; it is culture. Thus, the culture associated with a language cannot be acquired by simply learning about celebrations, folk songs, or customs of the communities in which the language is spoken. Culture is a much broader social force, inherently tied into many of the linguistic concepts taught in the second or foreign language classroom.

It is not by chance that the National Standards in Foreign Language Education Project of the United States has put culture at the forefront in second language teaching. The Project sustains that students cannot master a language until they have also mastered the culture. ${ }^{7}$ Language learners, according to Krasner, have to understand that linguistic competence is not enough; they need to be aware of when, where, who, how, why and what language is used in specific

6 Qtd.in: Tawara Goode, Sanjeev Socklingam, SethBronheim, Marc Brown and Wendy Jones, "A Planner's Guide: Infusing Principles, Content and Themes Related to Cultural and Linguistic Competence into Meetings and Conferences," Georgetown University Center for Child and Human Development, National Center for Cultural Competence, January 10, 2016, <http://nccc. georgetown.edu/documents/Planners_Guide.pdf>.

7 Oxana Dema and Aleidine Kramer Moeller, "Teaching Culture in the 21st Century Language Classroom,”DigitalCommons@University of Nebraska, Lincoln, <http://digitalcommons.unl. edu/teachlearnfacpub/ 181>, November 16, 2015. 
contexts. ${ }^{8}$ For instance, it is not appropriate to ask a complete stranger a question such as "How old are you?" or to say to the person, "Hey you, come here," unless the speaker occupies a position of authority that is socially recognized by the person being addressed and if such communicative behavior is necessary for getting an appropriate, immediate response.

The fact that humans are social beings is the fundamental reason why language and culture are such essential elements of their nature. Actually, when people utter words, they refer to common experiences because when communicating, they turn to their stock of shared knowledge of the world. This, language expresses cultural reality, and in turn, cultural reality is created through language. ${ }^{9}$

\section{The Unconscious Nature of Speech Behavior}

Wolfson ${ }^{10}$ makes a valid point in stating that insights into sociolinguistic rules, for non-native speakers of English(NNES), interacting with members of native English (NE) communities, could prove vital to encouraging tolerance and reducing negative stereotypes about other cultures. Presently, however, this is not possible in any systematic way because most sociolinguistic rules are largely below the level of conscious or intuitive analysis. What this means is that native speakers, although completely competent in using and interpreting their native language, are not even aware of the patterned nature of their own speech behavior.

This why native speakers may be able to judge the correctness or appropriateness of their language when interacting with nonnative speakers, by recognizing when there are deviations from the

8 Irene Krasner, "The Role of the Culture in Language Teaching," Dialog on Language Instruction, 13, 1-2 (1999): 79-88.

9 Claire Kramsch, Context and Culture in Language Teaching (Oxford: Oxford University Press, 1993) 3.

10 Nessa Wolfson, Perspectives, Sociolinguistics and TESOL (Boston, Massachusetts: Heinle and Heinle Publishers, 1989) 35. 
sociolinguistic rules. Nevertheless, they are unable to describe the rules of their own speech behavior spontaneously. This means that there is a significant discrepancy between knowing what can be said in different speech contexts, and what is actually said in actual social interactions in different contexts.

Understanding speech patterns is even more complex for people who are bilingual or bidialectal because they often switch from one code or language to the other without being at all aware of it. Blom and Gumperz (qtd. in Wolfson ${ }^{11}$ ) carried out a study in a small village of Norway, where they established - much to the disbelief and irritation of the local people - that "code switching" happened subconsciously. In that community, the local dialect, Ranamal, was regarded as an important sign of friendliness, equality and local identity, and was the preferred dialect, while Bokmal was considered the standard Norwegian dialect used in education, government, media communication and religion practices. The study revealed that, though the native speakers took Ranamal as the socially correct language in family and social gatherings, considerable code switching was taking place subconsciously, in contexts where that language variation was more practical. When recordings were played to the speakers, they were in disbelief and referred to the findings as irregular - the exception, not the norm. Nonetheless, further recordings revealed the same pattern, though the local inhabitants continued to deny what was actually taking place in their language exchanges.

What this study and several others of the like mentioned in Wolfson show is that native speakers are not aware of the language patterns that play out in the different socio-cultural contexts in which they use them. Consequently, even though they have strong and well-informed ideas about what they should say, this is not at all the same as knowing what they do say. This is because speech norms or

11 Wolfson, 37. 
community ideas concerning appropriate speech behavior cannot be equated with speech use, which is actually a pattern of behavior.

The unconscious level at which native speakers respond in diverse socio-cultural contexts, even when failing to recognize their speech patterns in such instances, is crucial to understanding the inter-workings of foreign language use and acquisition processes. Since many of the grammatical choices made by native speakers in spontaneous everyday conversation are dependent upon sociolinguistic contexts, and since these distinctions are not intuitively obvious, materials designed for the purpose of teaching language learners are often both artificial and misleading. ${ }^{12}$

English as a Foreign Language (EFL) learners are limited in their language learning because culture immersion is limited and often superficial. Paulson ${ }^{13}$ points out that it is typical of TESOL curricula to include instructions about the grammatical rules to follow for information questions, but they do not include any guidelines about what questions are appropriate or inappropriate to ask under different circumstances. Furthermore, Byram and Morgan ${ }^{14}$ call attention to the fact that the separation of language and culture is even more apparent in those textbooks that append cultural contents in the form of culture capsules or background notes, rather than integrating culture into the language covered in the units. Nevertheless, if the cultural patterns embedded in the language of native speakers are unconscious, then it is essential to ask what cultural patterns come up when foreign language users communicate in their own social contexts with native speakers of the foreign tongue.

If speakers of a foreign language both learn and use it in their own native speaking environments, with limited exposure to the foreign culture, then it is possible to assume that their native social

12 Wolfson, 43

13 Cristina Paulston, Implications of Language Learning Theory for Language Planning (Arlington: Center for Applied Linguistics, 1974) 14.

14 Michael Byram and Carol Morgan, Teaching-and-Learning Language-and-Culture (Clevendon: Multilingual Matters, 1994) 17. 
and cultural contexts are the ones that primarily mold the way they express themselves in the foreign language. This is a fundamental aspect that needs to be examined in the context of tourism, especially international tourism, where cultural and language dynamics may play out in unexpected distinctive ways.

\section{Pragmatics in Tourism Exolinguistic Service Interactions}

Yule describes pragmatics as "[t]he study of the relationships between linguistic forms and the users of those forms." ${ }^{15}$ A relevant example could be the use of the personal pronoun "tú" in familiar contexts and the formal "usted" by other Spanish speakers, whereas in Costa Rica, the use of "tu" "was found much less frequently in the past. In other countries that distinction is very important, so the pragmatics of using either of them correctly is very significant for them. Furthermore, Gric (quoted in Thomas) sustains that:

While syntax is the study of how linguistic forms are arranged in sequence, and semantics examines the relationship between linguistic forms and entities of the world, pragmatics is concerned with the notion of implicature, i.e. implied meaning as opposed to the mere lexical meaning expressed. ${ }^{16}$

Riley defines pragmatic failure as "misunderstandings leading to dissatisfaction or conflict, or occasionally, to great hilarity," ${ }^{17}$ while Thomas refers to the same concept as more closely tied to an individual's self-image, stating that these types of errors are more serious than grammatical errors associated with the speaker's level of linguistic proficiency. ${ }^{18}$

15 George Yule, Pragmatics (Oxford: Oxford University Press, 1996) 4.

16 Jenny Thomas, Meaning in Interaction: An Introduction to Pragmatics (Essex: Longman, 1995) 56.

17 Philip Riley, Language, Culture and Identity: An Ethnolinguistic Perspective (London and New

York: Continuum, 2007) 222.

18 Jenny Thomas, “Cross-Cultural Pragmatic Failure," Applied Linguistics, 4, 2 (1983):91-112. 
Pragmatic errors cause more "damage" because they are taken more personally than grammatical or linguistic errors. For instance, invading the personal space of someone who belongs to a culture in which respecting this space is mandatory can cause more irritation than ideas expressed with some degree of linguistic inaccuracy.

Under usual conditions, pragmatic failures are most likely to occur if there is a lack of understanding of culture; and it is in exolinguistic service encounters where pragmatic failure most commonly takes place. According to Riley, service encounters in tourism are a praxiological class of social interaction, where there is exchange of goods, services or knowledge. ${ }^{19}$ Customers or clients receive a service, and social agents or service providers offer the service. The role that each one assumes, and the socio-cultural context in which they are located are significant for understanding the interrelationships that play out. For instance, Riley states that in exolinguistic service encounters, there is asymmetry between the levels of communicative competence of the speaker and that of the hearer. He also points out that the prototypical case of exolinguistic discourse is commonly called "foreigner talk" (or "Native/Non-Native conversation"), where one of the participants does not have the same degree of mastery of the language as the other. ${ }^{20}$

Pragmatics of intercultural communication concerns the manner in which the various roles of the actors are carried out. Comparative studies of pragmatics between members of different cultures reveal that because each culture seems to have different preferences for modes of speech act behaviors, this leads to different culturally determined expectations and interpretations. That is why the concepts ethos and communicative virtues are so significant here. Ethos refers to the self-image that the speaker projects by means of discourse, filtered through the hearer's perceptions and responses. Worded differently, ethos refers to "the traits of character which a speaker has to display 19 Riley, 220.

20 Riley, 213. 
to an audience in order to make a good impression, and thereby assure that his/her speech will have a successful outcome." ${ }^{21}$ In view of that, Riley concludes that service encounters follow certain social patterns and that the way in which certain statements are uttered increases their socio-cultural significance. ${ }^{22}$ Therefore, linguistic competence by itself is not enough for mutual comprehension between foreign tourists and local service providers.

Being competent in a foreign language implies knowing the social and situational norms that govern interaction when native speakers use the language among themselves. As Aristotle affirmed, "[t]o win trust, it is necessary to demonstrate three principal characteristics: intelligence, virtue, and goodwill." 23 That idea is fundamental in the relationship between discourse performance, and various aspects of construction of social identity such as social categorization, membershipping, attitude formation, stereotyping, and accommodation. ${ }^{24}$

Communicative virtues - socially valued characteristics of speech - are considered the most important characteristics of discourse performance. Examples of those are politeness, friendliness, efficiency, clarity and directness. The difficulty in establishing a successful ethos and positive communicative virtues in cross-culturalcommunication is that they are socially defined and thus, vary across cultures and contexts; for instance, in a country like the United States, directness constitutes an appreciated communicative virtue, whereas in Costa Rica, directness is oftentimes perceived as harsh or unfriendly. Furthermore, in their study, Beebe and Taskahashi pointed out that many ESL learners of Japanese reported that their instructors had told them to be direct whenever they would speak English, and thus had led

21 Riley qtd. in Virginie André and Desiree Castillo, "The 'Competent Foreigner': A New Model for Foreign Language Didactics?" Bent Preisler, Anne Fabricius, et al., eds, The Consequences of Mobility (Roskilde: Roskilde University, 2005) 160.

22 Riley qtd. in Andres and Castillo, 160.

23 Riley, 213.

24 Riley, 216. 
them towards an over-simplified and stereotyped goal of acquiring the communicative virtue of directness in English-speaking encounters. ${ }^{25}$ The concepts plurilingualism and pluriculturalism are also meaningfulincross-culturalcommunicationserviceencounters. Coste, Moore and Zarate define these two terms as " $[t]$ he competence to communicate linguistically and to interact culturally [which is] possessed by an actor who masters, to differing degrees, numerous languages, and has to manage the totality of this language and cultural capital. ${ }^{26}$ This idea implies that second language speakers do not superimpose one language or culture upon the other, but must develop instead a plural competency.

Likewise, sociolinguist Hymes explains that it is not only important to view languages as a part of a speaking system, but also to analyze those systems from a socio-cultural standpoint. ${ }^{27}$ According to Hymes, communicative competence is acquired by knowing the rules that govern the interactions of the listener's community for the speaker to adapthis/her behavior accordingly — as a non-native speaker of the language.$^{28}$ Hence, plurilingualism and pluriculturalism are optimum goals for achieving successful pragmatic communication in exolinguisticservice encounters.

\section{The Role of Habitus in Intercultural Communication in Tourism}

Habitus is a Latin word which means condition (of the body); character; quality: style of dress, attire, disposition, state of feeling; habit. ${ }^{29}$ Bourdieu's concept of human habitus matches, in some way, the originalLatin meaning, except perhaps for the inclusion of "character."

25 Qtd. in Seiji Fukazawa, "Teaching and Learning Culture with AETs-What Cross-Cultural Pragmatics Can Tell Us," Bulletin of the Faculty of School Education, Hiroshima University 19, 1 (1997): 39-49.

26 Qtd. in Andres and Castillo, 162.

27 Hymes, 70.

28 Hymes, 70.

29 Dennis Shirley, "A Critical Review and Appropriation of Pierre Bourdieu's Analysis of Social and Cultural Reproduction," Journal of Education 168. 2 (1986): 96-112. 
For Bourdieu, habitus refers to socially acquired, embodied systems of dispositions and/or predispositions, implying that people's behavior is socially conditioned in their behavior. ${ }^{30}$

As part of a community, people go through a socialization process, and unconsciously develop ingrained mental dispositions about basic things such as ways of walking or speaking, and many other complex aspects such as deep structural classificatory and assessment propensities that are socially acquired and manifested in outlooks, opinions, and embodied phenomena. Habitus underlies such secondnature human characteristics, and their infinite possible variations in different historical and cultural settings. ${ }^{31}$

While habitus is derived from cultural conditioning, Bourdieu and Passeron ${ }^{32}$ refuse to equate it with its manifestation, nor is habitus considered to be as a fixed essence, operating like a computer program that determines mental or behavioral outcomes. This is because, in the authors' perception, people can reject notions that are prevalent in the society they live in; and they may choose to respond very differently from the people around them. Of course, the notion of habitus is very complex, and there are many levels in which it can be explored. The habitus of an individual is dynamic, changing as a person passes through different stages of life, participates in different groups and organizations, and experiences life in new places.

The above is especially true when an individual travels to other parts of the world where language, culture, and social customs are very different from their own, in which case, they are "out of their habitus." They may then find it difficult to know how to act, speak, and relate with the people, and to the events that they experience. According to Bourdieu, "Culturally coded patterns of tourist behavior partly emerge out of dispositions that evolve around class, gender,

30 Pierre Bourdieu and Loïc J. D. Wacquant. Respuestas. Por una antropología reflexiva (México: Grijalbo, 1995) 5.

31 Bourdieu and Wacquant, 5.

32 Pierre Bourdieu and Jean-Claude Passeron, Reproduction in Education Society and Culture (Beverly Hills, CA: Sage Publications, 1977) 85. 
ethnicity and sexuality, for instance." ${ }^{\prime 33}$ Nevertheless, while tourists may be in the predicament of being out of their habitus, they do have dispositions about how to act as tourists; this is sometimes referred to as the tourism habitus. That is, tourists have to negotiate meaning under different social and cultural contexts. Thus, it can be generally assumed, that there is goodwill and positive intentions among tourists to appreciate the host culture.

Tourism is unique in that, according to Jarworski and Thurlow, ${ }^{34}$ it transforms the banal into exotic and converts use-value into exchange value. In the tourism habitus, even what is trivial and uninteresting within and for the host society could be perceived as intriguing or magical by the tourists. In fact, Urry describes interactions taking place in tourism, in the following manner: "Not only does tourism involve face-to-face (or more mediated) forms of visitor-host interaction, like in many other types of service encounters, but the ultimate goods purchased by tourists during their travels are images, lifestyles, memories and their narrative enactments. ${ }^{35}$

The above comment by Urry reveals the nature of the sociocultural interaction of tourism and the role of habitus as tourists move into unknown social scenes and experience different ideologies, and social constructions of host societies. In like manner, for the native tourist service providers, there is a change in habitus because though they are in their own country and possess the acquired social norms of their society. They work within institutionalized settings where they are expected to act, interact and communicate differently by means of a foreign language.

Knowledge surrounding intercultural encounters with tourists can be for the service provider limited to a rather small range of seemingly irrelevant cultural aspects such as physical space, or

33 Bourdieu and Passeron, 30.

34 Adam Jaworski and Crispin Thurlow, Language and the Globalizing Habitus of Tourism (Washington: University of Washington, 2009) 2.

35 John Urry, The Tourist Gaze, 2nd ed. (London: Sage, 2002) 43. 
manners of greeting, or may involve more complex and significant factors such as religious taboos or expected norms in the quality of the service they offer. In addition, if they are expected to interact with the tourists in a foreign language, they are subjected to the socio-cultural norms that are implied in that language. Thus, tourist service providers are expected to express themselves and provide service to the tourists in a way that is understandable and appropriate from the perspective of the tourists.

Tourism is one of the largest branches of international trade, and it is a hallmark of globalization. ${ }^{36}$ Furthermore, tourism appears as the ideal industry for global capitalism because of its flexible, deeply semiotic and reflexive nature. ${ }^{37}$ It is flexible in the sense that the experience of being a tourist is essentially ephemeral and changing, making the tourist willing to accommodate to the anticipated exotic or "exoticized" experiences, as much as to some of the mishaps involved in order to appreciate the sceneries, cultures, and distinct kinds of interactions offered to them as desired commodities. On the other hand, following Rossi-Landi's understanding, it is semiotic because of the symbolic significance involved in the signs and sign systems that come into play when tourists interact with the members of the host community. ${ }^{38}$ Finally, tourism is defined as reflexive because of the well-organized and highly institutionalized networks that it is made of, which is what allows the industry to monitor, evaluate and develop the material and semiotic resources of each potential destination in the context of global tourism. ${ }^{39}$

Moreover, Jaworski and Thurlow state that "[t]ourism exemplifies a semiotically embedded service because, like advertising and marketing, a key part of what is actually produced and consumed in

36 Arjun Appadurai, "Disjuncture and Difference in the Global Cultural Economy," Theory, Culture and Society 7 (2003): 295.

37 Urry, 2.

38 Ferruccio Rossi-Landi, El lenguaje como trabajo y como mercado (Caracas: Monte Ávila, 1970) 22.

39 Urry, 2. 
tourism is the semiotic context of the service." ${ }^{40}$ This is to say that tourists not only use commodities, such as hotels and other services, but they also "consume" history, host-visitor interactions, images, lifestyles, memories and the conversations they share with their hosts. Then, among the goods purchased in tourism, there are not only those that are tangible but there are intangible commodities as well, as Urry specifically points out:

Material goods such as souvenirs, artefacts not unlike snippets of language formulae brought back from foreign trips are themselves (re-)packaged and promoted as useful props in the enactment of these performances, and they serve as an extension of the tourist gaze - the socially organized, systematized and 'disciplining' ways in which tourism is structured and learned. ${ }^{41}$

While it is useful to think of language, communication, and culture as commodities in the global tourism activity, it is also important to note that tourism plays a marked role, both as a product and as a producer of globalization, and thus in the tension that takes place in the areas of economy, capital and identity differentiations. This is because tourists are consumers of others' cultures, while the hosts present, perform, and/or recreate facets of their own culture for sale. Alternatively, as Jaworski and Thurlow put it: "It is in the singular interpersonal, intercultural exchanges between the touring and the toured that we find most forceful manifestations of the internalized, global order." ${ }^{42}$

Therefore, it seems appropriate to think of tourism as a structured and systematized activity, involving particular sets of codes, norms, expectations and hierarchies, which are contributing forces in the construction process of globalization. Furthermore, Jaworski and

40 Jaworski and Thurlow, 3.

41 Urry, 45.

42 Jaworski and Thurlow, 5. 
Thurlow point to the necessity of rethinking many key concepts in sociolinguistics and ethnolinguistics, in face of the dynamic changes that tourismand globalization are effecting in these fields. ${ }^{43}$ The concept of community, for example, in its traditional sense, refers mostly to people sharing a geographical space, as well as common ideologies, beliefs, services and ways of interacting. Nonetheless, with the advent of the Internet and accessible, rapid airline travel, communities are formed by people who have nothing in common except for a single unifying element, such as their interest in nature conservation, the liking for a form of art, or a political ideology.

What clearly comes up from the above examples is that globalization has brought drastic changes in the ways people think, act, create identities, and live, all of which point to the need for re-examining the conceptual models of Ethnolinguistics, and other areas of research, under the light of those changes. That is why Blommaert and Rampton place emphasis on two processes: the processes of entextualization, the process by which texts are produced by extracting discourse from its original context, and reifying it as a bounded object; and recontextualization, a process that extracts text, signs or meaning from its original context in order to introduce them in another context. ${ }^{44}$

Since the meaning of texts and signs depends upon the context, recontextualization implies a change in meaning, and communicative purposeas well. As mentioned above, Jaworskiand Thurlowemphasize that, "Tourism is a master of recontextualization: lifting the everyday into the realm of the fantastical, transforming the banal into the exotic and converting use-value into exchange-value., ${ }^{\prime 5}$ In this same line of thought, Bauman, one of the world's leading sociologists states that:

Tourism is both a vast movement of specific people (i.e. the tourists) and a metaphor for much of contemporary (Western) life: the

43 Jaworski and Thurlow, 2.

44 Qtd. in Jaworski and Thurlow, 2.

45 Jaworski and Thurlow, 2. 
'tourism syndrome' that is characterized by temporariness, a looseness of attachment to places and people and an endless 'grazing' (or consumption) of sensations and interactions. ${ }^{46}$

In fact, because of the mobility of people and knowledge, and other aspects of globalization, Jarworski and Thurlow affirm that many concepts of sociolinguists and ethnolinguistics need to be thought over all together. ${ }^{47}$

Habitus is recontextualized in tourism. The term tourism habitus is unique in explaining the underlying predispositions and social constructions that emerge from this activity. As Edensor states:

Tourism is a process, which involves the ongoing (re)construction of praxis and space in shared contexts. But this (re)production is never assured, for despite the prevalence of codes and norms, tourist conventions can be destabilized by rebellious performances, or by multiple, simultaneous enactions (sic) on the same stage. ${ }^{48}$

The author emphasizes that tourism is a manifestation of performances, both by the hosts and the tourists, in an attempt to sell the hosts' culture and everyday life experiences canned in an exotic and fantastical package. In that way both parties are, to some extent, actors who interact together under systematized rules or norms, while immersed in the tourism experience. Jaworski and Thurlow have also singled out that tourism interactions are "habituating, normative practices as instantiating an often playful performance of contact which, in turn, establishes a globalizing habitus for both tourists and their hosts," 49 and because the overall empirical effect of tourism habitus as a form of social order is constructed along lines of consumption and power,

46 Qtd. in Adrian Franklin, Tourism: An Introduction (London and Thousand Oaks, California: Sage, 2003) 207.

47 Jaworski and Thurlow, 2.

48 Tim Edensor, "Performing Tourism, Staging Tourism. Reproducing Tourist Space and Practice," Tourist Studies 1, 1 (2001): 59-81.

49 Jaworski and Thurlow, 3. 
individual interactions are not so clearly one-sided and clear-cut as traditionally assumed in sociolinguistics and ethnolinguistics theory.

In terms of power relations, though service providers occupy a sub-servant position, they are also in controlofthe interactions between them and the tourists by being the providers of local knowledge and culture. Tourists often feel insecure on tours where they are exposed to local customs and culture. In part, that insecurity goes with the newness of the tourists' experience which delineates the exoticism of the encounter and stimulates the touristic experience.

The tourism service providers, on the other hand, are very familiar with their surroundings, with the events that take place and perhaps, even with the routines of receiving tourists, answering their questions, and handling common problems. The interactions that play out between the tourists and the hosts go beyond the mere exchange of goods and services for money, entailing dynamic, sometimes uncertain results. This is where language, communication, and culture become both commodities and vehicles of exchange; this is also where the traditional place of language is dislocated. ${ }^{50}$

\section{Conclusion}

Culture and language are inseparable elements of the communication process. Furthermore, the complexity of speech behavior goes far beyond the scope of a stream of spoken words emitted by one individual and received by another. On the contrary, the interworking of culture and language produce meanings and levels of meaning where by the effectiveness of this communication depends on the shared cultural competence between the communicators. Furthermore, not all speech behavior is conscious. Studies have shown that in varying cultural context, individuals may do code switching, use paralanguage or even change pronunciation without realizing it. This unconscious

50 Jaworski and Thurlow, 5. 
nature of communication leads to one of the difficulties in teaching a foreign or second language because part of the speech behavior is unobserved, and therefore, one may have a difficult time producing it in the most adequate manner. When entering into the realms of intercultural communication, these aspects have even greater impact on speech behavior.

Habitus deals with the socially conditioned nature of one's behavior which frequently operates at an unconscious level. The habitus is not discarded as individuals carry out intercultural exchanges, and this could cause communication difficulty or failure, especially when done in a foreign language. On the other hand, awareness of being out of one's habitus could create greater sensitivity in the communication process and hence, strengthen the mutual desire to understand the messages given. This is especially true in the case of Costa Rican tourism, where the tourists come to the country and hence are out of their habitus, but may use English to communicate. This is also the case while the Costa Rican service providers are in their natural habitus, but have to use a foreign language in the interaction.

Along with habitus, there are other pragmatics in tourism exolinguistic service interactions. Pragmatic failure is quite common, but it is minimized by the willingness of the two parties to have successful outcomes. However, it is essential to lessen the impact of pragmatic failure, so that accurate communication is ensured and the desired outcome is obtained. Fortunately, along with the process of globalization, a rapidly growing tourism habitus is developing, where both the tourists and the service providers come together in an environment where expected norms exist, and both parties understand them. Nonetheless, because both language and culture are commodities of the tourism experience, there will always be unexpected elements in touristic intercultural interactions, making it necessary to look at language and communication in a broader scope, so that second and foreign language users are able to respond more effectively as service providers. 